\title{
Perlukah Kriteria Hipertensi Baru dan Target Pengendalian Tekanan Darah yang Lebih Agresif? Telaah Paska Studi SPRINT serta Panduan ACC/AHA 2017 dan ESH/ESC 2018
}

\author{
Bambang Widyantoro ${ }^{1}$
}

\section{Pendahuluan}

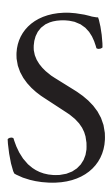

ejak dipublikasikan beberapa waktu lalu, studi SPRINT - yang meneliti luaran klinis dari upaya pengendalian tekanan darah (TD) yang intensif dibandingkan dengan pengendalian tekanan darah standar - telah menuai banyak komentar dan pemikiran dari berbagai kalangan. Studi ini menunjukkan bahwa pengendalian tekanan darah yang intensif dengan target TD sistolik $<120 \mathrm{mmHg}$ memiliki luaran klinis yang lebih baik berupa penurunan kejadian stroke, serangan jantung koroner, gagal jantung, serta angka mortalitas akibat kardiovaskular, dibandingkan dengan pengendalian tekanan darah standar dengan target TD sistolik $<140 \mathrm{mmHg}$, pada populasi hipertensi berusia $>50$ tahun yang memiliki peningkatan risiko

Departemen Kardiologi dan Kedokteran Vaskular, Universitas Indonesia/ Pusat Jantung Nasional Harapan Kita, Jakarta

I Anggota Pokja Hipertensi pada Perhimpunan Dokter Spesialis Kardiovaskular Indonesia (PERKI) dan anggota Pokja Penelitian dan Registri pada Perhimpunan Hipertensi Indonesia/Indonesian Society of Hypertension (PERHI/InaSH)

\section{Korespondensi:}

dr Bambang Widyantoro, SpJP(K)

Departemen Kardiologi dan Kedokteran Vaskular,

Universitas Indonesia/ Pusat Jantung Nasional Harapan Kita,

Jakarta

E-mail: bambang_ui@yahoo.com
(Indonesian J Cardiol. 2018;39:55-59)

kardiovaskular, non-diabetes dan tanpa riwayat penyakit serebrovaskular. ${ }^{1}$

Salah satu yang disorot adalah metode pengukuran tekanan darah tanpa pendampingan pada studi SPRINT - unattended office blood pressure (BP) measurement yang dianggap tidak realistis pada praktik sehari-hari dan menyatakan bahwa metode pengukuran tersebut memberi hasil yang lebih rendah dibandingkan pengukuran tekanan darah di klinik yang didampingi (attended office BP) yang biasa dilakukan sehari-hari, sehingga hasilnya tidak bisa dibandingkan dengan berbagai studi lain dengan metode pengukuran yang berbeda. $^{2,3}$ Sebagai pembanding, studi ACCORD dengan tujuan yang serupa namun pada populasi hipertensi dengan diabetes, atau studi SPS3 pada populasi hipertensi dengan riwayat stroke - yang menggunakan metode pengukuran TD di klinik dengan pendampingan - kedua studi ini tidak dapat menunjukkan superioritas dari pengendalian tekanan darah yang lebih intensif. ${ }^{4}$

Namun demikian, ACC/AHA bersama dengan perhimpunan hipertensi terkait di Amerika Serikat telah membuat panduan kriteria hipertensi yang baru (tabel 1) serta target pengendalian tekanan darah yang lebih agresif, 5 yang sebagian besar didasari atas hasil studi SPRINT. Panduan yang dipublikasikan pada bulan November 2017 kembali menuai banyak komentar, sehingga dunia akademis, saintis dan praktisi medis menunggu panduan yang dikeluarkan oleh belahan 
Tabel 1. Kategori TD pada orang dewasa (ACC/AHA 2017)*6

\begin{tabular}{lccc}
\hline & BP Category & SBP & DBP \\
\hline Normal & $<120 \mathrm{~mm} \mathrm{Hg}$ & and & $<80 \mathrm{mmHg}$ \\
Elevated & $120-129 \mathrm{~mm} \mathrm{Hg}$ & and & $<80 \mathrm{mmHg}$ \\
Hypertension & & or & \\
Stage I & $130-139 \mathrm{~mm} \mathrm{Hg}$ & or & $\geq 90-89 \mathrm{mmHg}$ \\
Stage II & $\geq 140 \mathrm{~mm} \mathrm{Hg}$ & $\mathrm{mm} \mathrm{Hg}$ \\
\hline
\end{tabular}

*individuals with SBP and DBP in 2 categories should be designated to the higher BP category.

$\mathrm{BP}$ indicates blood pressure (based on an average of $\geq 2$ careful readings obtained on $\geq 2$ occasions); DBP, diastolic blood pressure; and SBP systolic blood pressure

dunia eropa, yang diharapkan dapat mengimbangi dengan kebijakan yang lebih moderat.

Akhirnya, tepat pada tanggal 9 Juni 2018, panduan ESH-ESC dipaparkan pada plenary session di European Society of Hypertension (ESH) annual scientific meeting di Barcelona. Saya berkesempatan merasakan suasana gemuruh tepuk tangan para peserta, ketika mendengar bahwa ESH/ESC memutuskan untuk tidak mengubah kriteria hipertensi (tabel 2), namun tetap membuat beberapa rekomendasi perubahan penting serta memberikan panduan untuk target pengendalian tekanan darah yang lebih ketat sesuai dengan stratifikasi risiko kardiovaskular yang menyertai. ${ }^{7}$

Tulisan ini akan menyoroti beberapa hal yang penting untuk dipelajari serta ditelaah bersama untuk kepentingan kita di tanah air, meliputi; (1) Bagaimana cara pengukuran tekanan darah yang direkomendasikan?; (2) Apakah kita perlu mengadopsi perubahan kriteria hipertensi versi ACC-AHA 2017? Ataukah memilih kategori moderat ala ESC-ESH 2018?; (3) Berapa target pengendalian tekanan darah yang optimal?; serta (4) Kebijakan publik apa yang perlu ditelurkan untuk mengatasi beban kasus hipertensi di Indonesia?

\section{Metode pengukuran tekanan darah}

Panduan hipertensi dari berbagai perhimpunan memang belum memberikan rekomendasi yang tegas tentang metode pengukuran tekanan darah. Namun ada beberapa prinsip dasar yang perlu ditekankan, meliputi: (1) Jenis alat pengukur TD; direkomendasikan menggunakan mercury-free devices, dengan kalibrasi rutin untuk alat pengukur TD digital dan menggunakan upper-arm cuffs (cuff lengan atas) dengan ukuran yang sesuai. Penggunaan alat pengukur TD digital nonmercury, tidak hanya meminimalisir subjektivitas pengukuran, namun juga ramah lingkungan. (2) Posisi dan persiapan pasien; Dalam 30 menit sebelum pengukuran disarankan untuk tidak mengkonsumsi alkohol, kafein dan tidak merokok. Posisi yang dianjurkan adalah duduk rileks bersandar dengan posisi lengan yang akan diukur di atas meja setinggi posisi jantung. (3) Pengukuran serial; Disarankan untuk melakukan pengukuran 3 kali dengan selang waktu minimal 1 menit, dan diambil rerata pengukuran ke- 2 dan ke-3 sebagai hasil akhir. Pengukuran serial ini sangat dianjurkan, karena berbagai studi menunjukkan

Tabel 2. Kategori TD pada orang dewasa (ESC/ESH 2018) 7

\begin{tabular}{|c|c|c|c|}
\hline BP Category & Systolic $(\mathrm{mmHg})$ & & Diastolic $(\mathrm{mmHg})$ \\
\hline Optimal & $<120$ & and & $<80$ \\
\hline Normal & $120-129$ & and/or & $80-84$ \\
\hline High Normal & $130-139$ & and/or & $85-89$ \\
\hline Grade 1 hypertension & $140-159$ & and/or & $90-99$ \\
\hline Grade 2 hypertension & $160-179$ & and/or & $100-109$ \\
\hline Grade 3 hypertension & $\geq 180$ & and/or & $\geq 110$ \\
\hline Isolated systolic hypertension & $\geq 140$ & and & $<90$ \\
\hline
\end{tabular}


perbedaan sekitar 4-7 $\mathrm{mmHg}$ antara pengukuran pertama dengan kedua-ketiga. Pada kampanye awareness TD dalam rangka bulan hipertensi sedunia, progam May Measurement Month 2017 yang digagas oleh International Society Hypertension dan diikuti oleh Indonesia - yang direpresentasikan oleh Perhimpunan Hipertensi Indonesia (PERHI/InaSH) yang digawangi oleh Perhimpunan Dokter Spesialis Kardiovaskular Indonesia (PERKI), Perhimpunan Nefrologi Indonesia (PERNEFRI) dan Perhimpunan Dokter Spesialis Saraf Indonesia (PERDOSSI) - dari 70,000 lebih data pengukuran TD di Indonesia didapatkan perbedaan TD 4-5 $\mathrm{mmHg}$ antara pengukuran pertama dengan keduaketiga, sehingga rerata pengukuran kedua dan ketigalah yang diambil sebagai hasil akhir. ${ }^{8}$

Dan yang terakhir; (4) Apakah pengukuran tekanan darah dilakukan di klinik dengan pendampingan atau tanpa pendampingan? Untuk hal ini memang belum ada kesepakatan dari para ahli. Mengapa metode pengukuran TD pada studi SPRINT dikritisi? Pada studi ini disebutkan bahwa tekanan darah di klinik dilakukan oleh pasien sendiri di ruang tertutup tanpa pendampingan dari tenaga medis. Hal ini diperkirakan akan memberi rasa tenang dan nyaman - setara dengan pengukuran TD di rumah (home BP measurement - yang dianggap bebas dari efek "white coat"), sehingga hasil pengukuran TD bisa lebih rendah dibandingkan dengan pengukuran di klinik dengan didampingi oleh tenaga medis di ruangan yang sama. ${ }^{9}$ Menyikapi pandangan ini, tim peneliti SPRINT baru saja mempublikasikan data post-analytic dan meng-klaim bahwa protokol studi ini sedianya tidak mengangkat isu metode pengukuran attended vs. unattended. Dikatakan bahwa evaluasi akhir menunjukkan adanya 4 jenis cara pengukuran yang dilakukan di lebih dari 30 site studi, yaitu subyek tidak pernah didampingi baik saat istirahat maupun saat pengukuran $(\mathrm{N}=4082)$; selalu didampingi $(\mathrm{N}=2247)$; tidak didampingi saat fase istirahat sebelum diukur $(\mathrm{N}=1746)$ dan tidak didampingi saat pengukuran $(\mathrm{N}=570)$; dan hasilnya menunjukkan tidak ada perbedaan rerata TD pada semua kelompok tersebut serta adanya hasil konsisten akan luaran klinis di seluruh kelompok meski dengan metode pengukuran yang berbeda. ${ }^{10}$ Meski di satu sisi publikasi ini dapat menetralisir isu attended vs. unattended, namun tak pelak data ini juga menuai kritik lanjutan yang menyoroti variasi cara pengukuran TD pada studi penting ini.
Bagaimana implikasinya bagi kita? Hasil dan isu yang berkembang paska studi SPRINT dan studi lain perlu dicermati dengan seksama. Butir-butir rekomendasi tentang metode pengukuran TD yang terstandar kiranya sangat penting untuk dibuat dalam bentuk konsensus bersama di tanah air, sehingga dapat dilakukan dengan konsisten dan diadopsi secara nasional, salah satunya agar dapat meminimalisir ketidakakuratan data. Kita tentu tidak ingin mengulangi kejadian adanya perbedaan prevalensi hipertensi di Indonesia hasil RISKESDAS 2007 dan 2013 (31.7\% vs 25.8\%) - tanpa adanya program intervensi yang signifikan dari pemangku kepentingan - yang akhirnya tidak ideal untuk dibandingkan karena ternyata kedua survey tersebut menggunakan metode dan alat pengukuran TD yang berbeda. ${ }^{11}$

\section{Kriteria dan klasifikasi hipertensi}

Sampai tahun 2015, panduan hipertensi di Indonesia baik yang dikeluakan oleh Perhimpunan Dokter Spesialis Kardiovaskular (PERKI) maupun Perhimpunan Hipertensi Indonesia (PERHI) 2017 masih menetapkan $\mathrm{TD} \geq 140 / 90 \mathrm{mmHg}$ sebagai batas kriteria hipertensi, mengadopsi panduan ESC/ESH 2013.12-15

Bagaimana paska dikeluarkannya panduan AHA 2017 dan ESC 2018? Seyogyanya para ahli di bidang ini perlu duduk bersama untuk membahas lebih lanjut. Penulis berpendapat bahwa untuk kriteria diagnosis hipertensi, batasan $\geq 140 / 90 \mathrm{mmHg}$ masih layak dipertahankan seperti panduan ESC 2018, dengan alasan bahwa kriteria batasan TD yang lebih rendah (seperti batasan $\geq 130 / 80 \mathrm{mmHg}$ pada panduan AHA 2017) untuk diagnosis hipertensi dapat menimbulkan efek psikologis dan kecemasan yang pada "penderita" yang kemudian dapat membuat TD makin tinggi. Yang sebaiknya direvisi adalah target pengendalian tekanan darah.

\section{Target pengendalian tekanan darah}

Menentukan target pengendalian tekanan darah yang optimal memang bukan hal yang mudah. Isu tentang J-curve pada penderita hipertensi dengan penyakit jantung koroner (PJK) dan juga diabetes dari beberapa studi besar perlu ditelaah kembali. Mitos yang telah lama beredar di masyarakat (bahkan diaminkan oleh 
sebagian praktisi medis) bahwa semakin lanjut usia maka kenaikan tekanan darah boleh ditolerir sampai 150/90 $\mathrm{mmHg}$ sebaiknya segera diluruskan. Berbagai studi telah menunjukkan bahwa tekanan darah $>140 / 90 \mathrm{mmHg}$ berhubungan erat dengan meningkatnya kejadian stroke dan serangan jantung koroner, sehingga rekomendasi ESC 2018 yang mentargetkan < 140/90 pada fase awal dan dilanjutkan ke $<130 / 85$ bila pasien toleran (tanpa melihat usia) layak dipertimbangkan untuk diadopsi.7 Pada kasus hipertensi dengan komorbid tertentu dapat juga diberikan target yang berbeda sesuai bukti ilmiah yang tersedia. Bahwa kebijakan ini bila diikuti akan memberatkan beban pemerintah (cq. Kementerian Kesehatan) dalam mencapai target proporsi pengendalian TD memang demikian adanya, mengingat capaian pengendalian TD dengan target sebelumnya pun belum tercapai. Namun mengingat beban biaya dan sosial yang ditimbulkan oleh kejadian stroke, serangan jantung koroner serta gagal ginjal yang memerlukan dialisis rutin akibat hipertensi yang tidak terkontrol, maka para pemangku kepentingan perlu untuk mempertimbangkan hal ini.

\section{Kebijakan publik yang diperlukan}

Hipertensi dan berbagai penyulit yang ditimbulkannya jelas sudah menjadi masalah kesehatan sangat besar yang perlu mendapat perhatian di tanah air. Hal ini menjadi tantangan besar untuk semua pemangku kepentingan. Organisasi profesi dan perhimpunan seminat yang terkait memiliki tanggung jawab moral untuk berperan aktif. Apa yang bisa dilakukan? Di antaranya - namun tidak terbatas pada - (1) Duduk bersama melakukan telaah kritis dan menyusun panduan atau konsensus hipertensi nasional; (2) Advokasi bersama ke pemerintah (cq. Kementerian Kesehatan); (3) Sosialisasi dan edukasi kepada praktisi medis melalui pendidikan kedokteran berkelanjutan (PKB) serta ke masyarakat luas tentang hipertensi dan upaya pencegahan serta pengendaliannya; termasuk kampanye pola hidup sehat dan menurunkan konsumsi garam; serta (4) Tidak lupa akan pentingnya kita memiliki data epidemiologis maupun klinis yang diperoleh melalui penelitian yang terstruktur, baik berbasis populasi maupun klinik, sebagai acuan untuk menentukan arah kebijakan di masa depan.

Sebagai penutup, menjawab judul editorial ini, untuk panduan di tanah air penulis berpendapat bahwa batasan kriteria hipertensi yang selama ini dianut masih tetap relevan, dan belum cukup bukti untuk justifikasi membuat batasan TD yang lebih rendah sebagai kriteria hipertensi. Namun revisi target pengendalian TD yang lebih agresif untuk menurunkan komplikasi kardioserebro-reno-vaskular sangat layak dipertimbangkan.

\section{Daftar Pustaka}

1. Group SR, Wright JT, Jr., Williamson JD, Whelton PK, Snyder JK, Sink KM, Rocco MV, Reboussin DM, Rahman M, Oparil S, Lewis CE, Kimmel PL, Johnson KC, Goff DC, Jr., Fine LJ, Cutler JA, Cushman WC, Cheung AK and Ambrosius WT. A Randomized Trial of Intensive versus Standard Blood-Pressure Control. N Engl J Med. 2015;373:2103-16.

2. Myers MG and Campbell NR. Unfounded concerns about the use of automated office blood pressure measurement in SPRINT. J Am Soc Hypertens. 2016;10:903-905.

3. Agarwal R. Implications of Blood Pressure Measurement Technique for Implementation of Systolic Blood Pressure Intervention Trial (SPRINT). $J$ Am Heart Assoc. 2017;6.

4. Krakoff LR. A Tale of 3 Trials: ACCORD, SPRINT, and SPS3. What Happened? Am J Hypertens. 2016;29:10203.

5. Whelton PK, Carey RM, Aronow WS, Casey DE, Jr., Collins KJ, Dennison Himmelfarb C, DePalma SM, Gidding S, Jamerson KA, Jones DW, MacLaughlin EJ, Muntner P, Ovbiagele B, Smith SC, Jr., Spencer CC, Stafford RS, Taler SJ, Thomas RJ, Williams KA, Sr., Williamson JD and Wright JT, Jr. 2017 ACC/AHA/AAPA/ABC/ACPM/AGS/APhA/ ASH/ASPC/NMA/PCNA Guideline for the Prevention, Detection, Evaluation, and Management of High Blood Pressure in Adults: A Report of the American College of Cardiology/American Heart Association Task Force on Clinical Practice Guidelines. J Am Coll Cardiol. 2018;71:e127-e248.

6. Whelton PK, Carey RM, Aronow WS, Casey DE, Jr., Collins KJ, Dennison Himmelfarb C, DePalma SM, Gidding S, Jamerson KA, Jones DW, MacLaughlin EJ, Muntner P, Ovbiagele B, Smith SC, Jr., Spencer CC, Stafford RS, Taler SJ, Thomas RJ, Williams KA, Sr., Williamson JD and Wright JT, 
Jr. 2017 ACC/AHA/AAPA/ABC/ACPM/AGS/ $\mathrm{APh} / \mathrm{ASH} / \mathrm{ASPC} / \mathrm{NMA} / \mathrm{PCNA}$ Guideline for the Prevention, Detection, Evaluation, and Management of High Blood Pressure in Adults: Executive Summary: A Report of the American College of Cardiology/American Heart Association Task Force on Clinical Practice Guidelines. J Am Coll Cardiol. 2018;71:2199-2269.

7. WIlliams B and Mancia G. 2018 ESC/ESH Guidelines on Management of Arterial Hypertension. Eur Heart Journal, In Press. 2018.

8. Widyantoro B, Turana Y, Barrack R, Sofiatin Y and Situmorang TD. May Measurement Month 2017: Indonesian Report. 2018.

9. Mancia G and Kjeldsen SE. Adopting Systolic Pressure Intervention Trial (SPRINT)-like office blood pressure measurements in clinical practice. J Hypertens. 2017;35:471-472.

10. Johnson KC, Whelton PK, Cushman WC, Cutler JA, Evans GW, Snyder JK, Ambrosius WT, Beddhu S, Cheung AK, Fine LJ, Lewis CE, Rahman M, Reboussin DM, Rocco MV, Oparil S, Wright JT, Jr. and Group SR. Blood Pressure Measurement in SPRINT (Systolic Blood Pressure Intervention Trial). Hypertension. 2018;71:848-857.

11. Kesehatan BPdP and RI KK. Riset Kesehatan Dasar 2013. 2013.

12. Erwinanto. Definisi dan Klasifikasi Hipertensi. Dalam: Turana Y; Widyantoro B. (Editor). Buku Ajar Hipertensi: Indonesian Society of Hypertension; 2017.

13. Soenarta AA and Widyantoro B. Hipertensi Sistemik: Mekanisme, Diagnosis dan Tatalaksana. Dalam: Yuniadi Y; Siswanto, BB; Hermanto DY (Editor); Buku ajar Kardiovaskular. Jakarta: Departemen Kardiologi dan Kedokteran Vaskular FKUI; 2017.

14. PERKI. Panduan Tatalaksana Hipertensi: Pokja hipertensi PP PERKI; 2015.

15. Mancia G, Fagard R, Narkiewicz K, Redon J, Zanchetti A, Bohm M, Christiaens T, Cifkova R, De Backer G, Dominiczak A, Galderisi M, Grobbee DE, Jaarsma T, Kirchhof P, Kjeldsen SE, Laurent S, Manolis AJ, Nilsson PM, Ruilope LM, Schmieder RE, Sirnes PA, Sleight P, Viigimaa M, Waeber B, Zannad F, Redon J, Dominiczak A, Narkiewicz K, Nilsson PM, Burnier M, Viigimaa M, Ambrosioni E, Caufield M, Coca A, Olsen MH, Schmieder RE, Tsioufis C, van de Borne P, Zamorano JL, Achen- bach S, Baumgartner H, Bax JJ, Bueno H, Dean V, Deaton C, Erol C, Fagard R, Ferrari R, Hasdai D, Hoes AW, Kirchhof P, Knuuti J, Kolh P, Lancellotti P, Linhart A, Nihoyannopoulos P, Piepoli MF, Ponikowski P, Sirnes PA, Tamargo JL, Tendera M, Torbicki A, Wijns W, Windecker S, Clement DL, Coca A, Gillebert TC, Tendera M, Rosei EA, Ambrosioni E, Anker SD, Bauersachs J, Hitij JB, Caulfield M, De Buyzere M, De Geest S, Derumeaux GA, Erdine S, Farsang C, Funck-Brentano C, Gerc V, Germano G, Gielen S, Haller H, Hoes AW, Jordan J, Kahan T, Komajda M, Lovic D, Mahrholdt H, Olsen MH, Ostergren J, Parati G, Perk J, Polonia J, Popescu BA, Reiner Z, Ryden L, Sirenko Y, Stanton A, Struijker-Boudier H, Tsioufis C, van de Borne P, Vlachopoulos C, Volpe M and Wood DA. 2013 ESH/ESC guidelines for the management of arterial hypertension: the Task Force for the Management of Arterial Hypertension of the European Society of Hypertension (ESH) and of the European Society of Cardiology (ESC). Eur Heart J. 2013;34:2159219. 